Check for updates

Cite this: RSC Adv., 2018, 8, 26399

\title{
Biomethanation of blast furnace gas using anaerobic granular sludge via addition of hydrogen $\dagger$
}

\author{
Ying Wang, $\dot{\dagger}^{\mathrm{a}}$ Chenzhu Yin, $\dot{\dagger}^{\mathrm{a}}$ Ye Liu, ${ }^{a}$ Mengjiao Tan, ${ }^{\mathrm{a}}$ Kazuya Shimizu, \\ Zhongfang Lei, (D) ${ }^{a}$ Zhenya Zhang, (D) *a Ikuhiro Sumi, ${ }^{\text {b }}$ Yasuko Yao ${ }^{c}$ \\ and Yasuhiro Mogi ${ }^{\mathrm{b}}$
}

The high concentrations of $\mathrm{CO}$ (toxic) and $\mathrm{CO}_{2}$ (greenhouse gases) in blast furnace gas (a by-product of steelworks) reflect its low calorific value. In this study, anaerobic granular sludge was used to convert carbon from blast furnace gas to methane via exogenous hydrogen addition. The inhibition of methane production by $\mathrm{CO}$ partial pressure $\left(P_{\mathrm{CO}}\right)$ was found to start from $0.4 \mathrm{~atm}$. The intermediate metabolites from $\mathrm{CO}$ to methane including acetate, propionate, and $\mathrm{H}_{2}$ accumulated at higher $\mathrm{CO}$ concentrations in the presence of 2-bromoethanesulfonic acid. After the introduction of $\mathrm{H}_{2}$ and blast furnace gas, although the hydrogen partial pressure $\left(P_{\mathrm{H}_{2}}\right)$ up to 1.54 atm resulted in the maximum $\mathrm{CH}_{4}$ yield, the whole system was not stable due to the accumulation of a large amount of volatile fatty acids. The optimum $P_{\mathrm{H}_{2}}$ on $\mathrm{CH}_{4}$ production from the simulated blast furnace gas, $5.32 \mathrm{mmol} \mathrm{g}$ VSS, was $^{-1}$ VS determined at $0.88 \mathrm{~atm}$ in this study.

Received 6th June 2018

Accepted 17th July 2018

DOI: $10.1039 / c 8 r a 04853 c$

rsc.li/rsc-advances
For the treatment of BFG, absorbents can be developed for $\mathrm{CO}_{2}$ capture from BFG to recover the carbon source for integrated steelworks. ${ }^{2}$ Besides, hydrogen can be produced from $\mathrm{CO}$ in BFG through water-gas shift reaction (as shown in reaction 3 below) regardless of $\mathrm{CO}_{2}$ is captured or separated. ${ }^{7}$ However, strict reaction conditions need to be controlled such as the specific catalyst development and high temperature. The mixtures of $\mathrm{CO}, \mathrm{CO}_{2}$, and $\mathrm{H}_{2}$ can also be used as sources for biofuels production by microorganisms, like ethanol, ${ }^{8}$ volatile fatty acids ${ }^{9}$ and 2,3-butanediol. ${ }^{10}$

Compared with $\mathrm{H}_{2}, \mathrm{CH}_{4}$ is also a good source of clean energy, and its storage cost is only about $1 / 3$ of $\mathrm{H}_{2} \cdot{ }^{11}$ Higher quality of fuel will be obtained through biomethanation of $\mathrm{CO}_{2}$ and $\mathrm{CO}$ from BFG, which could be further utilized as heating fuel or power generation for steel industry. Therefore, this form of carbon recycling not only saves costs but also helps reduce GHG. In addition, there are ready-made pipe networks for $\mathrm{CH}_{4}$ transportation and distribution. As per biological methods, a moderate temperature and pressure, and a low energy consumption are their merits. Besides, the high specificity of enzymes involved may bring about higher product yields and less by-products. Biological conversion of $\mathrm{CO}_{2}$ (ref. 8 and 9) and/ or $\mathrm{CO}^{12}$ to $\mathrm{CH}_{4}$ by anaerobic microorganisms have been studied and confirmed previously, such as Bugante, E. C. et al. ${ }^{13}$ used a column bioreactor to convert BFG to methane under thermophilic conditions. Two steps are generally involved in this process: the conversion from $\mathrm{CO}$ to $\mathrm{CO}_{2}$ and methane, and then extra $\mathrm{H}_{2}$ is added to the reactor for accomplishing the conversion of $\mathrm{CO}_{2}$ to methane. The related reaction processes for
${ }^{a}$ Graduate School of Life and Environmental Sciences, University of Tsukuba, 1-1-1, Tennodai, Tsukuba, Ibaraki 3058572, Japan. E-mail: zhang.zhenya.fu@u.tsukuba. ac.jp; Fax: +8129853 4712; Tel: +81298534712

${ }^{b} J F E$ Steel Cooperation, 1, Kawasaki-cho, Chuo-ku, Chiba 2600835, Japan 'JFE Techno-Research Cooperation, 2-7-1 Otemachi, Chiyoda-ku, Tokyo 1000004, Japan

$\dagger$ Electronic supplementary information (ESI) available. See DOI: 10.1039/c8ra04853c

\$ These authors contributed equally to this work. 
carboxydotrophic microorganisms and hydrogenotrophic methanogens are shown as follows. ${ }^{14}$

$$
\begin{gathered}
4 \mathrm{CO}+2 \mathrm{H}_{2} \mathrm{O} \rightarrow \mathrm{CH}_{4}+3 \mathrm{CO}_{2}, \Delta G^{0}=-53 \mathrm{~kJ} \mathrm{~mol}^{-1} \\
\mathrm{CO}+3 \mathrm{H}_{2} \rightarrow \mathrm{CH}_{4}+\mathrm{H}_{2} \mathrm{O}, \Delta G^{0}=-151 \mathrm{~kJ} \mathrm{~mol}^{-1} \\
\mathrm{CO}+\mathrm{H}_{2} \mathrm{O} \rightarrow \mathrm{H}_{2}+\mathrm{CO}_{2}, \Delta G^{0}=-20 \mathrm{~kJ} \mathrm{~mol}^{-1} \\
4 \mathrm{CO}+2 \mathrm{H}_{2} \mathrm{O} \rightarrow \mathrm{CH}_{3} \mathrm{COOH}+2 \mathrm{CO}_{2}, \Delta G^{0}=-176 \mathrm{~kJ} \mathrm{~mol}^{-1}(4) \\
2 \mathrm{CO}+2 \mathrm{H}_{2} \rightarrow \mathrm{CH}_{3} \mathrm{COOH}, \Delta G^{0}=-67 \mathrm{~kJ} \mathrm{~mol}^{-1} \\
\mathrm{CH}_{3} \mathrm{COOH} \rightarrow \mathrm{CH}_{4}+\mathrm{CO}_{2}, \Delta G^{0}=-31 \mathrm{~kJ} \mathrm{~mol}^{-1} \\
4 \mathrm{H}_{2}+\mathrm{CO}_{2} \rightarrow \mathrm{CH}_{4}+2 \mathrm{H}_{2} \mathrm{O}, \Delta G^{0}=-130.7 \mathrm{~kJ} \mathrm{~mol}^{-1}
\end{gathered}
$$

The above reactions about methane production include direct reaction (reactions (1), (2), and (7)) and indirect reaction (reactions (3)-(6)). For the indirect methane production, it mainly has two steps: precursors $\left(\mathrm{H}_{2}\right.$ or acetate) formation from $\mathrm{CO}, \mathrm{H}_{2}$ or $\mathrm{CO}_{2}$ by bacteria, and biomethanation of the precursors by methanogens. It can be seen that BFG could not be completely converted to methane without exogenous $\mathrm{H}_{2}$ addition, due to the co-existence of high concentration of $\mathrm{CO}_{2}$ in the BFG. Up to now, little information could be found on methane production from the mixture of BFG and $\mathrm{H}_{2}$ gases under mesophilic conditions. Here, exogenous $\mathrm{H}_{2}$ can be obtained from hydrogen containing industrial exhaust gases, such as coke oven gas (COG),${ }^{15}$ the byproduct from the coke making process, contains around $54-59 \%$ of $\mathrm{H}_{2}$. Most of the COG is directly discharged into the air, resulting in seriously environmental pollutions. Therefore, the conversion of $\mathrm{H}_{2}$ from COG by microorganisms to methane would be more sustainable. For the hydrogen from electrolysis of fluoride-contaminated wastewater, ${ }^{16}$ in order to obtain only hydrogen, electrocoagulation technology can be applied to treat hydrofluoric acid wastewater by using renewable electricity without oxygen production. Exogenous $\mathrm{H}_{2}$ can also be obtained from in situ anaerobic corrosion of metallic iron, ${ }^{17}$ and the hydrogen produced by iron corrosion could serve as electron-donor for hydrogen-consuming microorganisms.

In the biological methods for treating $\mathrm{CO}$ or $\mathrm{CO}_{2}$, pure culture is sensitive to the changes of environment or strict sterilization conditions. ${ }^{14-16}$ However, it is well known that mixed culture presents rich functions, such as non-sterile conditions, high ability to adapt to different components of syngas, ${ }^{18}$ existence of rich variety of microorganisms and low cost than pure culture. ${ }^{19}$ These advantages make it more suitable for application in industry. Anaerobic granular sludge (AGS) with excellent settling property, capability of high biomass retention and ability to treat high-strength organic wastewater is a promising technology that has attracted more and more attention. ${ }^{20}$ It is usually used in upflow anaerobic sludge blanket (UASB), expanded granular sludge bed (EGSB) and internal circulation (IC) reactors to treat wastewaters at high organic loading rates. The structure of AGS is favorable to resist $\mathrm{CO}$ inhibition as the outer layer is dominated by heterogeneous population and bacteria, and the inner layer consists of large numbers of archaea like methanogens. ${ }^{21}$ AGS has been used in the mixed culture to convert $\mathrm{CO}$ to hydrogen ${ }^{22}$ or methane. ${ }^{23}$ However, until now, there is no documentation on the biomethanation of $\mathrm{CO}$ and $\mathrm{CO}_{2}$ from $\mathrm{BFG}$ by AGS via addition of exogenous $\mathrm{H}_{2}$ in mixed cultures at mesophilic conditions. Since the anaerobic digestion of wastewater by AGS in above-mentioned reactors involving multiple steps requires the participation of various microorganisms, it is possible for the microorganisms in the anaerobic reactor to convert $\mathrm{CO}$ and $\mathrm{CO}_{2}$ in the BFG to methane, while addition of exogenous hydrogen is assumed to promote the biomethanation of BFG more thoroughly.

Based on the above considerations, the present study aimed to investigate the feasibility of biomethanation of $\mathrm{BFG}$ by exogenous $\mathrm{H}_{2}$ addition. The potential of AGS for converting $\mathrm{CO}$ and $\mathrm{CO}_{2}$ to $\mathrm{CH}_{4}$ was examined. In addition, it is important to understand the possible effect of $\mathrm{CO}$ on the activity of the microorganisms and the $\mathrm{CO}$ methanation routes. Since $\mathrm{H}_{2}$ is a possible inhibitor to the anaerobic process, it is challenging to add both BFG and hydrogen in the reactors at the same time. In this study, the mechanisms for enhancing $\mathrm{CH}_{4}$ production by AGS via exogenous $\mathrm{H}_{2}$ addition were explored using batch tests.

\section{Materials and methods}

\section{Sludge source}

The sludge used in this study was obtained from a mesophilic Expanded Granular Sludge Blanket (EGSB) reactor treating brewery wastewater (Asahi, Ibaraki, Japan) and was stored at $4{ }^{\circ} \mathrm{C}$. The major physicochemical characteristics of the AGS were as follows: total suspended solids (TSS) $11.7( \pm 0.5) \mathrm{g} \mathrm{L} \mathrm{L}^{-1}$, volatile suspended solids (VSS) $9.9( \pm 0.3) \mathrm{g} \mathrm{L}^{-1}$, and $\mathrm{pH} 6.8$ $( \pm 0.1)$ with extracellular proteins of $128.1( \pm 2.9) \mathrm{mg} \mathrm{g}^{-1} \mathrm{VSS}$, extracellular polysaccharide of $9.4( \pm 0.3) \mathrm{mg} \mathrm{g}^{-1} \mathrm{VSS}$, and total organic carbon (TOC) of $679.9( \pm 0.8) \mathrm{mg} \mathrm{g}^{-1}$ VSS, respectively.

\section{Experimental set-ups}

\section{Methanogenic potential of AGS}

As $\mathrm{CO}$ and $\mathrm{CO}_{2}$ in $\mathrm{BFG}$ were designed to be converted to methane, batch experiment 1 was firstly conducted to investigate the methanogenic potential of the AGS sampled from the EGSB reactor. In this part, acetoclastic, carboxydotrophic and hydrogenotrophic methanogenic activities of the AGS in anaerobic cultures were tested in cylindrical pressure bottles $(4.4 \mathrm{~cm}$ in diameter, $7 \mathrm{~cm}$ in height) with a volume of $110 \mathrm{ml}$. $50 \mathrm{ml}$ of the basic medium ${ }^{24}$ and granular sludge (washed with phosphate buffer) were loaded into the bottles to reach a final volatile solids (VSS) concentration of $2 \mathrm{~g} \mathrm{~L}^{-1}$. The $\mathrm{pH}$ of the mixture was then adjusted to 7.2 with $2 \mathrm{M} \mathrm{NaOH}$. In order to create anaerobic conditions, the bottles were flushed with pure $\mathrm{N}_{2}$ gas for 3 min after being capped and sealed with butyl rubber stoppers. A certain volume of $\mathrm{N}_{2}$ was removed from the bottle and replaced by an equivalent volume of $\mathrm{CO}\left(\mathrm{CO}_{2}\right.$, or $\left.\mathrm{H}_{2}\right)$ using a gas tight syringe to obtain the required partial pressure in the headspace. Different substrates were filled ${ }^{25}$ in the headspace 
with a volume of $60 \mathrm{ml}$ or in the liquid, including R1-sodium acetate $(30 \mathrm{mM})$ for acetoclastic methanogenic activity, $\mathrm{R} 2-\mathrm{H}_{2} /$ $\mathrm{CO}_{2}(80 / 20,2.5 \mathrm{~atm})$ for hydrogenotrophic methanogenic activitiy, R3-CO/ $\mathrm{N}_{2} \quad(20 / 80,1$ atm $)$ for carboxydotrophica methanogenic activity, R4-CO/ $\mathrm{H}_{2} / \mathrm{N}_{2}(20 / 64 / 16,1$ atm), or $\mathrm{R} 5-\mathrm{CO} / \mathrm{CO}_{2} / \mathrm{H}_{2} \quad(20 / 16 / 64,1$ atm $)$ for carboxydotrophicb methanogenic activity. The detailed operation conditions are shown in Table S1. $\dagger$ Among the bottles, R4 was designed to investigate the effect of $\mathrm{H}_{2}$ on $\mathrm{CO}$ fermentation under mesophilic conditions. The bottles with granular sludge and medium only (without gas substance) were used as the control (R0). These bottles were incubated in a thermostatic water bath oscillator at $37 \pm 2{ }^{\circ} \mathrm{C}$ and $100 \mathrm{rpm}$. All the tests were performed in triplicate.

\section{Effect of CO partial pressure on methane production by AGS}

To investigate the effect of $\mathrm{CO}$ partial pressure $\left(P_{\mathrm{CO}}\right)$ on methane production from $\mathrm{CO}$ and the possible pathway involved, the experiments were divided into two parts, with the scales and procedures being similar as the above except for that the VSS of AGS was $4 \mathrm{~g} \mathrm{~L}^{-1}$. The first part (batch experiment 2) was conducted to observe the effect of CO partial pressure $\left(P_{\mathrm{CO}}\right)(0,0.1$, $0.2,0.4,0.8 \mathrm{~atm})$ on methane production. In this experiment the headspaces of the bottles were purged with the mixture of $\mathrm{CO}$ and $\mathrm{N}_{2}$ at different ratios to obtain the required initial partial pressures of CO. The second batch experiment (batch experiment 3) was performed for 7 days to explore the $\mathrm{CO}$ conversion route under different $P_{\mathrm{CO}}(0,0.2,0.4,0.6,0.8,1 \mathrm{~atm})$ with the methanogens inhibitor, $25 \mathrm{mM}$ 2-bromoethanesulfonic acid $(\mathrm{BES})^{26}$ being added. The impact of BES on the pathways of CO conversion to $\mathrm{CH}_{4}$ was summarized Fig. S1. $\dagger^{14}$

\section{Effect of exogenous $\mathrm{H}_{2}$ partial pressure on methane production from blast furnace gas}

In this experiment, the scales and procedures were similar with the batch experiment 1 , which investigated the effect of exogenous $\mathrm{H}_{2}$ partial pressure on methane production from BFG by using AGS. The compositions of simulated blast furnace gas (TOMOE SHOKAI Co., LTD, Japan) consist of $\mathrm{CO}, \mathrm{CO}_{2}, \mathrm{H}_{2}$, and $\mathrm{N}_{2}$ at a volume ratio of $\mathrm{CO} / \mathrm{CO}_{2} / \mathrm{H}_{2} / \mathrm{N}_{2}=22 / 22 / 4 / 52$. Besides BFG ( $1 \mathrm{~atm}, P_{\mathrm{CO}}$ was $0.22 \mathrm{~atm}$ ) in the headspace of the bottles, exogenous $\mathrm{H}_{2}$ was also added into each bottle up to a final hydrogen partial pressure $\left(P_{\mathrm{H}_{2}}\right)$ of $0.04 \mathrm{~atm}, 0.88 \mathrm{~atm}$, and 1.54 atm, respectively (with a total pressure being adjusted to $2.6 \mathrm{~atm}$ with $\mathrm{N}_{2}$ ). The detailed operation conditions are shown in Table $\mathrm{S} 2 . \dagger$ In this study, soluble total organic carbon (STOC) was measured and used in the carbon balance analysis.

\section{Analysis and chemicals}

Total suspended solids (TSS) and volatile suspended solids (VSS) were determined according to the Standard Methods. ${ }^{26}$ Two gas chromatographs (Shimadzu GC-8A, Japan) equipped with TCD were used to detect the concentrations of gaseous components. For $\mathrm{H}_{2}, \mathrm{CH}_{4}$, and $\mathrm{CO}_{2}$, the temperatures for the detector and injector were both $60{ }^{\circ} \mathrm{C}$, and the column temperature was $80^{\circ} \mathrm{C}$ with nitrogen being as the carrier gas.
For $\mathrm{CO}$ analysis, the detector and injector temperatures were both $170{ }^{\circ} \mathrm{C}$, and the column temperature was $80{ }^{\circ} \mathrm{C}$ with helium as the carrier gas. Volatile fatty acids (VFAs) concentrations were analyzed by a Shimadzu GC-14B/FID, and the column and the injector temperatures were set at $150{ }^{\circ} \mathrm{C}$ and $190{ }^{\circ} \mathrm{C}$, respectively with nitrogen being the carrier gas. In this study, the concentrations of VFAs were expressed as the equivalent carbon values calculated from the theoretical formula of each VFA component. And the carbon content of VSS was calculated using $\mathrm{C}_{5} \mathrm{H}_{7} \mathrm{O}_{2} \mathrm{~N}^{27}$

\section{Results and discussion}

\section{Methanogenesis potential of AGS under the tested conditions}

During the anaerobic biomethanation process of gases with different compositions, it was observed that AGS obviously possessed hydrogenotrophic and acetoclastic methanogenic potentials $(18.31 \pm 1.2 \mathrm{mmol}$ per $\mathrm{g}$ VSS per $\mathrm{d}$ and $6.58 \pm$ $0.38 \mathrm{mmol}$ per $\mathrm{g}$ VSS per $\mathrm{d}$, respectively, Fig. 1), which are similar with previous researches. ${ }^{22,24}$ In order to investigate the carboxydotrophic potential of the AGS used in this study, R3 and R5 were prepared and tested. As seen, AGS also exhibited a promising carboxydotrophic potential $(1.19 \pm 0.03 \mathrm{mmol}$ per $\mathrm{g}$ VSS per $\mathrm{d}$ and $5.56 \pm 0.26 \mathrm{mmol}$ per $\mathrm{g}$ VSS per $\mathrm{d}$ ) even though the microorganisms from AGS might not adapt to CO as energy source in comparison to $\mathrm{H}_{2}$. For all runs, no lag phase was detected during $\mathrm{CH}_{4}$ production (Fig. S2(a) $\dagger$ ). It was worth mentioning that during the conversion of $\mathrm{CO} / \mathrm{N}_{2}$, $\mathrm{CO}$ was the only substrate, while a very small amount of $\mathrm{H}_{2}$ and VFAs (data not shown) were detected, possibly due to that they were the intermediates for $\mathrm{CH}_{4}$ production.

The CO metabolism by microorganisms from AGS was somehow influenced by the presence of $\mathrm{CO}_{2}$ and/or $\mathrm{H}_{2}{ }^{18,28}$ although it is thermodynamically feasible (reaction (2)) for methane production from $\mathrm{CO}$ and $\mathrm{H}_{2}$. In the process of $\mathrm{CO}$ fermentation under mesophilic conditions, the effect of $\mathrm{H}_{2}$ has been rarely reported. ${ }^{28}$ Compared with $\mathrm{R} 3$, the presence of hydrogen (R4) led to a slower trend of CO consumption which

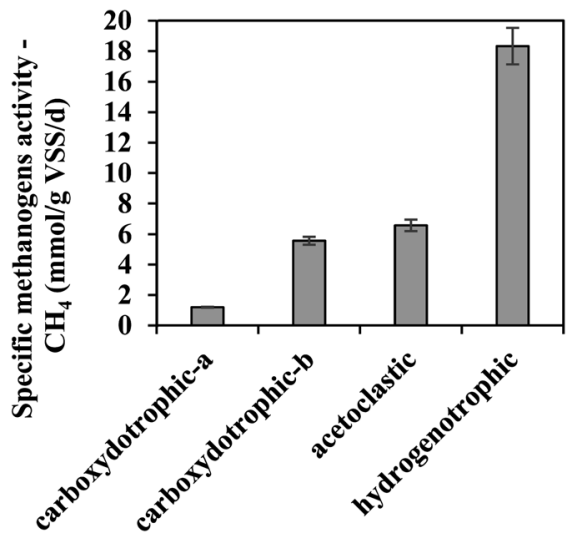

Fig. 1 Anaerobic biomethanation potential of AGS used in this study at $37{ }^{\circ} \mathrm{C}$. The substrates for carboxydotrophic-a, carboxydotrophic-b, acetoclastic, and hydrogenotrophic activities were $\mathrm{CO} / \mathrm{N}_{2}, \mathrm{CO} / \mathrm{CO}_{2} /$ $\mathrm{H}_{2}$, sodium acetate, and $\mathrm{H}_{2} / \mathrm{CO}_{2}$, respectively. 
presented negatively influence (Fig. S2(b) $\dagger$ ). Probably, CO was in part consumed during the production of the intermediates (e.g., $\mathrm{H}_{2}$ and acetate) for methanogenesis (reactions (3) and (4)). If $\mathrm{H}_{2}$ is an intermediate product, the presence of extra $\mathrm{H}_{2}$ in $\mathrm{R} 4$ is not conducive to the smooth progress of reaction (3). Assuming acetate is the intermediate, it may be formed from extra $\mathrm{H}_{2}$ and $\mathrm{CO}$ through reaction (5), and the consumption of $\mathrm{CO}$ in reaction (5) is slower than that of reaction (3) since 2 moles and 4 moles of $\mathrm{CO}$ are required to participate in the formation of 1 mole of acetate, respectively. In addition, by measuring VFAs concentrations, it accumulated at $109.5 \mathrm{~h}$ in R4 but not in R3 and R5 (data not shown). A similar phenomenon was noticed by Heiskanen et al. who applied Butyribacterium methylotrophicum to convert different gas substrates to biofuels (mainly acetate), ${ }^{29}$ and found that butyric acid production was increased after the supplementation of hydrogen into CO. However, the CO consumption rate in $\mathrm{R} 5$ was not affected by the supplementation of $\mathrm{CO}_{2}$ and $\mathrm{H}_{2}$, probably attributable to that $\mathrm{CO}_{2}$ reacted with $\mathrm{H}_{2}$ first (reaction (7)), eliminating the negative impact of CO consumption to some extent. Compared with R3, R4 seemed to have increased methane production that might be caused by the addition of hydrogen, stimulating the production of $\mathrm{CO}_{2}$ from the organics contained in the $\mathrm{AGS}^{30}$ and then the formation of $\mathrm{CH}_{4}$. According to a previous study, ${ }^{28}$ the addition of hydrogen would not promote the direct methanogenic CO conversion in reaction (2). The microbial population presented in AGS could rapidly convert $\mathrm{CO}_{2}$ into methane within $15.5 \mathrm{~h}$ in R5; however, the extra $\mathrm{CO}_{2}$ production detected from $37.5 \mathrm{~h}$ presented a similar increasing trend as that in R3 (Fig. S2(c) $\dagger$ ). This extra $\mathrm{CO}_{2}$ in $\mathrm{R} 5$ might be from $\mathrm{CO}$ and AGS itself. In R3, if calculated according to the reaction (1) which assumes that $\mathrm{CO}$ can be completely converted to $\mathrm{CH}_{4}$ and other intermediates, the produced methane $\left(0.56 \pm 0.09 \mathrm{mmol} \mathrm{g}^{-1} \mathrm{VSS}\right)$ was lower than the theoretical value $\left(1.34 \pm 0.04 \mathrm{mmol} \mathrm{g}^{-1} \mathrm{VSS}\right)$. This observation is attributable to that many intermediates were simultaneously generated from CO during the methanation process. At $109.5 \mathrm{~h}$, the intermediates have not been completely utilized.

From the above results, it can be concluded that AGS possessed a great potential for the conversion of $\mathrm{CO}$ and $\mathrm{CO}_{2}$ to methane. And supplementation of $\mathrm{H}_{2}$ to $\mathrm{CO}$ as substrate might lead to the accumulation of VFAs.

\section{Effect of CO partial pressure on methane production by AGS}

Fig. 2 shows the relationship between $P_{\mathrm{CO}}$ and methane production from CO. In general, more methane was accumulated when $P_{\mathrm{CO}}$ was lower than 0.2 atm at the initial stage (within $96 \mathrm{~h}$ ). Being similar with other reports, ${ }^{12,31}$ the methane production rate was found to be obviously inhibited when $P_{\mathrm{CO}}$ was higher than $0.4 \mathrm{~atm}$. When the pressure was $0.4 \mathrm{~atm}$, the varying trend could be divided into two phases. During the $96 \mathrm{~h}$ after starting this test, the cumulative methane production from different reactors followed a descending order as reactors at 0.2 atm $>0.1 \mathrm{~atm}>0.4 \mathrm{~atm}>0.8 \mathrm{~atm}$, illustrating that $P_{\mathrm{CO}} \geq 0.4 \mathrm{~atm}$ presented an inhibitory effect on methane production by AGS. After 96 hours' operation, due to that CO was gradually

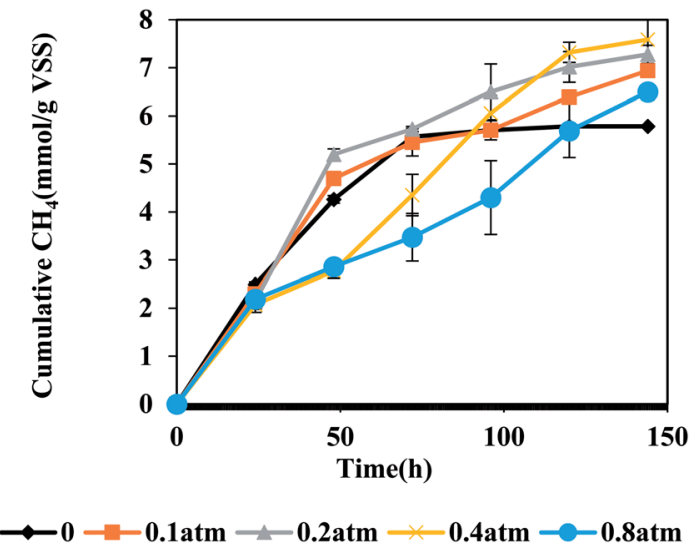

Fig. 2 Effect of CO partial pressure (atm) on methane production from $C O$ by AGS.

consumed by the microorganisms in the reactors, the partial CO pressure in the reactor gradually decreased and the inhibition was relieved to some extent. Therefore, the cumulative methane production under $P_{\mathrm{CO}}$ of $0.4 \mathrm{~atm}$ exceeded those from $0.2 \mathrm{~atm}$ and 0.1 atm reactors. However, it was different from the flocculant digested sludge in which the methanogens were inhibited at a $P_{\mathrm{CO}}$ of 0.25 atm. ${ }^{12}$ This observation reflects that the special dense structure of AGS is favorable for the resistance of CO inhibition. Along with the operation, the methane production at $P_{\mathrm{CO}}>0.4$ atm gradually increased and even exceeded the control. This observation is possibly due to that CO was gradually consumed by the microorganisms in the reactor, and the partial CO pressure in the reactor gradually decreased and the inhibition was relieved to some extent, then CO could be used by the microorganisms and converted to methane. It has been speculated that $\mathrm{CO}$ in the anaerobic reactor can be first converted by bacteria into some intermediates and then produce $\mathrm{CH}_{4}$ and $\mathrm{CO}_{2}$ by methanogens. ${ }^{23}$ The $\mathrm{CO}$ consumptions at different partial pressures are shown in Fig. S3.†

To explore the pathways from $\mathrm{CO}$ to methane and elucidate the effect of $\mathrm{CO}$ partial pressure on the intermediates produced, the gaseous components and VFAs were measured and recorded, respectively. Seen from Fig. 3(a), the concentrations of VFAs (129$247 \mathrm{mg} \mathrm{C}$ per L) on day 7 in all the bottles containing CO were obviously higher than that of the control (106 mg C per L), demonstrating an increasing trend with the increase in $P_{\mathrm{CO}}$. This observation indicates that VFAs could be produced from CO by bacteria when methanogens were inhibited by BES. The VFAs species and proportion of each individual VFA on day 7 were also examined. As seen from Fig. 3(b), no matter under which $P_{\mathrm{CO}}$ condition, the dominant VFA was acetate ranging from $47 \%$ to $68 \%$. From the control to $1 \mathrm{~atm}$ of $\mathrm{CO}$, the second largest amount of individual VFA changed from isovaleric acid $(18 \%$ in the control and $10 \%$ at $0.2 \mathrm{~atm}$ of $\left.P_{\mathrm{CO}}\right)$ to propionic acid $(16 \%$ at 0.4 atm, $33 \%$ at $0.6 \mathrm{~atm}, 36 \%$ at $0.8 \mathrm{~atm}, 35 \%$ at $1 \mathrm{~atm}$ of $\left.P_{\mathrm{CO}}\right)$. This phenomenon can be explained from the following two aspects. (1) In the presence of BES, the fermentation products of organic matter contained in AGS (control) were VFAs, especially acetate and isovaleric acid in this study. (2) With the increase of substrate 


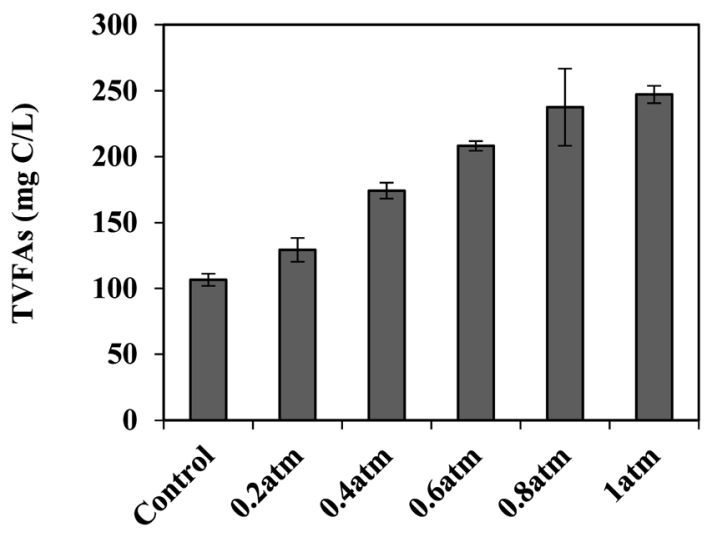

b

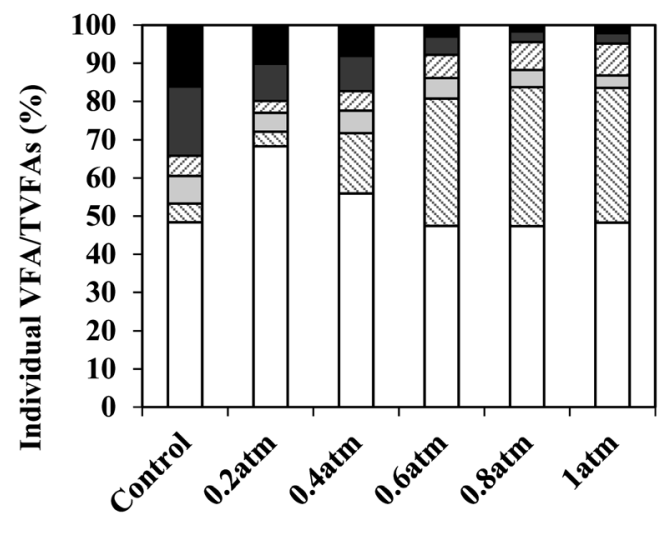

口n-HVa $\square \mathrm{i}-\mathrm{HVa} \square \mathrm{n}-\mathrm{HBu} \square \mathrm{i}-\mathrm{HBu}$ बHPr $\square \mathrm{HAc}$

Fig. 3 Effect of $\mathrm{CO}$ partial pressure (atm) on intermediates formation from $\mathrm{CO}$ in the presence of BES at $37^{\circ} \mathrm{C}$ on day 7: (a) VFAs, and (b) percentage of individual VFA species to the total VFAs(TVFAs).

(CO) addition to the reactor, acetate and propionate were the main intermediates of the CO conversion, which is partially in agreement with the findings by Navarro et al. ${ }^{14,25}$ who identified an acetate-producing bacterium ${ }^{31}$ and a propionate producing bacterium $^{32}$ after a long-time exposure to high CO concentrations. In addition, hydrogen was detected in the gas phase. CO has been claimed to be converted to methane via acetate (acetogenic CO-oxidizing pathway) as the precursor under mesophilic conditions, while via hydrogen (hydrogenotrophic CO-oxidizing pathway) under thermophilic conditions. ${ }^{26}$ Table 1 summarizes the related contents of acetate, propionate and $\mathrm{H}_{2}$. In this study, $\mathrm{H}_{2}$ was produced from all the $P_{\mathrm{CO}}$ conditions, which might be the intermediate when $P_{\mathrm{CO}}$ was higher than $0.2 \mathrm{~atm}$ in the headspace as a similar amount of $\mathrm{H}_{2}$ was detected in the control and the $P_{\mathrm{CO}}$ at $0.2 \mathrm{~atm}$ reactors. It has been pointed out that the carboxydotrophic activity was insignificant when both inhibitors (BES and vancomycin) were present at the same time; still, $\mathrm{H}_{2}$ could be detected, illustrating that hydrogen-producing bacteria were not inhibited in the presence of the above two inhibitors. ${ }^{25}$ Among these three intermediates, acetate (reactions (4) and (5)) was considered as the major one due to its highest content; however, the $\mathrm{H}_{2} / \mathrm{CO}_{2}$ pathway (reactions (3) and (7)) may be co-existing. ${ }^{33}$

The above results showed that when $P_{\mathrm{CO}}<0.2 \mathrm{~atm}$, methane production from CO by AGS was not obviously affected. Conversely, $P_{\mathrm{CO}}>0.4 \mathrm{~atm}$ started to inhibit the activity of methanogens. The conversion of $\mathrm{CO}$ to methane was mainly via acetate as intermediate probably accompanied by the $\mathrm{H}_{2} / \mathrm{CO}_{2}$ pathway.

\section{Effect of exogenous $\mathrm{H}_{2}$ partial pressure on methane production from blast furnace gas}

High $P_{\mathrm{CO}}$ presented inhibition on methane production, thus CO should be controlled at a low concentration in the anaerobic system. In this study, the CO partial pressure in BFG is about $0.22 \mathrm{~atm}$, slightly higher than $0.2 \mathrm{~atm}$ which has been demonstrated to be a partial pressure without obviously inhibitory effect on methanogens. Due to the slight difference between $0.22 \mathrm{~atm}$ and $0.2 \mathrm{~atm}$, the CO in BFG was not diluted in the experiments and its initial partial pressure was controlled at $0.22 \mathrm{~atm}$ in this test. The effect of exogenous $\mathrm{H}_{2}$ partial pressures on methane production from BFG by AGS is shown in Fig. 4(a). For the control, there was almost no lag phase which was similar with a previous report. ${ }^{34}$ Obviously, the lag period for methane production at $P_{\mathrm{H}_{2}}=0.88 \mathrm{~atm}$ and $1.54 \mathrm{~atm}$ was about $42 \mathrm{~h}$, suggesting that the anaerobic microbes need some adaptation time to accommodate to the BFG and $\mathrm{H}_{2}$ environment. For BFG at $P_{\mathrm{H}_{2}}$ of $0.04 \mathrm{~atm}$, this lag period lasted $71 \mathrm{~h}$, ending up with slightly more methane than the control. The methane production was $2.01 \mathrm{mmol} \mathrm{g}^{-1}$ VSS, $5.32 \mathrm{mmol} \mathrm{g}^{-1}$ VSS and $5.57 \mathrm{mmol} \mathrm{g}^{-1}$ VSS at $P_{\mathrm{H}_{2}}$ of $0.04 \mathrm{~atm}, 0.88$ atm and 1.54 atm, respectively. During the entire process, the highest methane production from BFG was obtained at $P_{\mathrm{H}_{2}}$ of $1.54 \mathrm{~atm}$, therefore addition of exogenous $\mathrm{H}_{2}$ favors methane generation. In addition, under the $P_{\mathrm{H}_{2}}$ of $1.54 \mathrm{~atm}$ condition, only $4.7 \%$ higher methane production was obtained than that under $P_{\mathrm{H}_{2}}$ of 0.88 atm condition, probably due to the formation of other intermediate products. The maximum $\mathrm{H}_{2}, \mathrm{CO}$ consumption and methane production rates are summarized in Table 2 . The maximum $\mathrm{CH}_{4}$ production rate of $4.08 \pm 0.71 \mathrm{mmol}$ per $\mathrm{g}$ VSS per $\mathrm{d}$ and $4.19 \pm 0.54 \mathrm{mmol}$ per $\mathrm{g}$ VSS per $\mathrm{d}$ were both achieved

Table 1 Main products detected in the reactors under different CO partial pressures in the presence of BES

$$
P_{\mathrm{CO}}(\text { atm })
$$

\begin{tabular}{|c|c|c|c|c|c|c|}
\hline Main product & Control & 0.2 & 0.4 & 0.6 & 0.8 & 1 \\
\hline $\mathrm{HPr}\left(\mathrm{mmol} \mathrm{g}^{-1} \mathrm{VSS}\right)$ & $0.11 \pm 0.02$ & $0.10 \pm 0.01$ & $0.59 \pm 0.02$ & $1.44 \pm 0.03$ & $1.80 \pm 0.02$ & $1.82 \pm 0.05$ \\
\hline
\end{tabular}



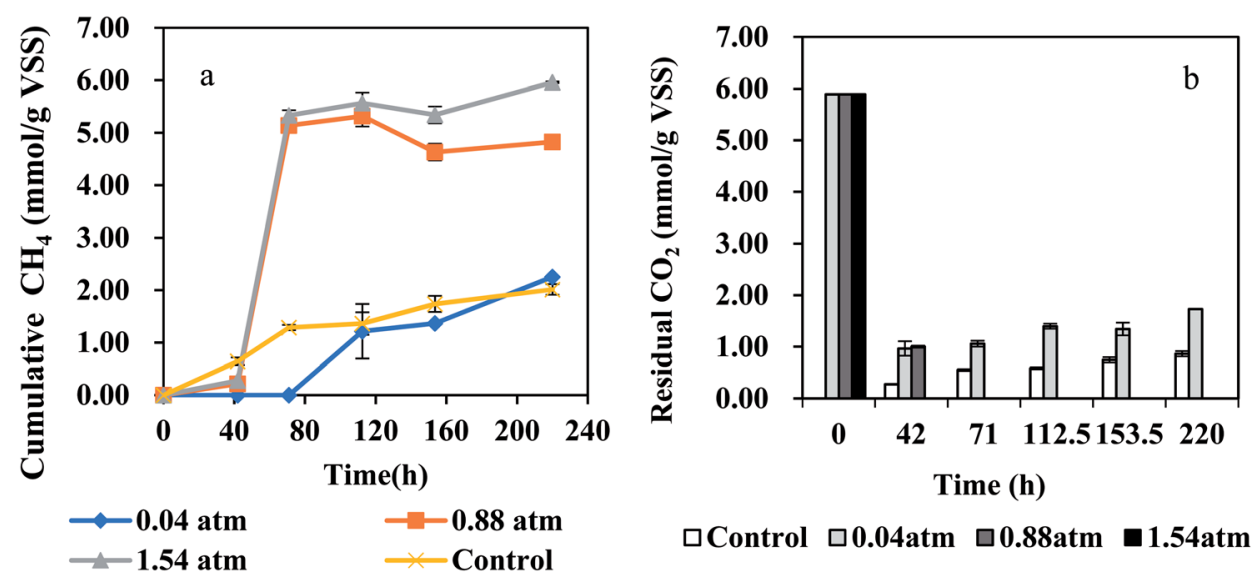

Fig. 4 Effect of $\mathrm{H}_{2}$ partial pressure (atm) on BFG fermentation by $\mathrm{AGS}$ at $37^{\circ} \mathrm{C}$ : (a) $\mathrm{CH}_{4}$, and (b) $\mathrm{CO}_{2}$.

under $P_{\mathrm{H}_{2}}$ of 0.88 atm or 1.54 atm on day 3 . The different inoculum or other conditions might result in the different time for achieving the maximum methane production rate. For example, in a continuous CO-converting reactor at $35{ }^{\circ} \mathrm{C},{ }^{20}$ the seeded anaerobic granules from a UASB plant treating fruit processing wastewater produced $\mathrm{CH}_{4}$ ranging from $0.49 \pm$ $0.1 \mathrm{mmol}$ per $\mathrm{g}$ VSS per $\mathrm{d}$ to $4.77 \pm 1.21 \mathrm{mmol}$ per $\mathrm{g}$ VSS per d during 100 days' operation, when operated at $P_{\mathrm{CO}}$ in the gas feeding (CO: $30-60 \%)$ of $(0.42-0.96) \pm 0.6$ atm and gas recirculation flow of $0-69 \mathrm{~L} \mathrm{~h}^{-1}$. As for the disaggregated sludge during 45 days' continuous $\mathrm{CO}$ injection to the headspace, its $\mathrm{CH}_{4}$ specific activity was $0.7 \pm 1.3 \mathrm{mmol}$ per $\mathrm{g}$ VSS per $\mathrm{d}$ on day 30 and $5.5 \pm 1.2 \mathrm{mmol}$ per $\mathrm{g}$ VSS per $\mathrm{d}$ on day 45 , respectively. ${ }^{\mathbf{1 1}}$ Even though the values obtained in this study are relatively lower than the above-mentioned $4.77 \pm 1.21 \mathrm{mmol}$ per $\mathrm{g}$ VSS per $\mathrm{d}$ and $5.5 \pm 1.2 \mathrm{mmol}$ per $\mathrm{g}$ VSS per $\mathrm{d}$, it took only 3 days to reach the maximum methane production rate, far shorter than the 97 days and 45 days reported in the previous works.

The $\mathrm{H}_{2}$ consumption rates under all tested groups increased with the increase in $\mathrm{H}_{2}$ partial pressure at a shaking speed of $100 \mathrm{rpm}$ which may control the hydrogen gas-liquid mass transfer during the methanogenesis. ${ }^{35}$ Hydrogen gas-liquid mass transfer limitation has been commonly observed in anaerobic reactors. ${ }^{36}$ In this study hydrogen gas-liquid mass transfer was obviously the limiting factor, as the hydrogen consumption rate was proportional to initial $P_{\mathrm{H}_{2}}$. As for the CO consumption rate, there was no significant difference between $P_{\mathrm{H}_{2}}$ of 0.88 atm and $1.54 \mathrm{~atm}$ conditions, possibly due to its low concentration in BFG. In order to make the reactions (1)-(7) thermodynamically feasible, additional hydrogen which could react with $\mathrm{CO}_{2}$ is favorable for the $\mathrm{CO}$ consumption no matter in direct or indirect methane production from CO. $\mathrm{CO}_{2}$ in BFG was fully utilized at $71 \mathrm{~h}$ and $42 \mathrm{~h}$ when $P_{\mathrm{H}_{2}}$ was at 0.88 atm and 1.54 atm, respectively (Fig. 4(b)). $\mathrm{CO}_{2}$ was consumed by $84 \%$ at $42 \mathrm{~h}$ when the initial $P_{\mathrm{H}_{2}}$ was $0.04 \mathrm{~atm}$, which later slightly increased and was not fully utilized, most probably due to the fact that $\mathrm{CO}_{2}$ was one of the products during the methanogenesis in the reactions (1), (3), (4), (6). This further suggests the necessity of exogenous hydrogen addition since it is beneficial for the consumption of $\mathrm{CO}$ and $\mathrm{CO}_{2}$ in BFG.

Esquivel-Elizondo et al. ${ }^{8}$ compared the effects of $\mathrm{CO}_{2}$ and $\mathrm{H}_{2}$ on CO metabolism using pure and mixed cultures (anaerobic sludge was acclimated to $\mathrm{CO}$ ) and claimed that the main products were acetate and ethanol. In the pure cultures the additional $\mathrm{H}_{2}$ did not promote acetate production which was opposite to the phenomenon in the mixed culture. A possible explanation is that, $\mathrm{CO}$ dehydrogenase (CODH), the enzyme that catalyzes the reversible reduction of $\mathrm{CO}$ to $\mathrm{CO}_{2}$, possesses hydrogenase activity. Thus, the activity of hydrogenases in the pure culture of carboxidotrophs could be redundant. Previous studies with pure cultures also reported that $\mathrm{H}_{2}$ was not consumed along with CO. ${ }^{35,36}$ In this study, the target product was methane by using AGS (mixed culture). From the changes in VFAs species under different $P_{\mathrm{H}_{2}}$ conditions (Fig. S4 $\dagger$ ), the coexistence of $\mathrm{H}_{2}$ may influence the balance between VFAs production and consumption to some extent. At initial $P_{\mathrm{H}_{2}}$ of $1.54 \mathrm{~atm}$, not only some increase in methane production (Fig. 4) but also VFAs accumulation were detected. This phenomenon may explain why only a slight increase $(4.7 \%)$ in methane production was achieved at $P_{\mathrm{H}_{2}}$ of 1.54 atm in comparison to $P_{\mathrm{H}_{2}}$ of 0.88 atm condition. Another two reactions ((8) and (9)) can also be used to explain the changes in VFAs under different $P_{\mathrm{H}_{2}}$. In order to make the reactions (8) and (9) thermodynamically

Table 2 The maximum hydrogen and carbon monoxide consumptions, and methane production rates under different $\mathrm{H}_{2}$ partial pressures

\begin{tabular}{|c|c|c|c|}
\hline$P_{\mathrm{H}_{2}}$ & $\begin{array}{l}\text { CO consumption rate } \\
(\mathrm{mmol} \text { CO per } \mathrm{g} \text { VSS per } \mathrm{d})\end{array}$ & $\begin{array}{l}\mathrm{H}_{2} \text { consumption rate } \\
\left(\mathrm{mmol} \mathrm{H}_{2} \text { per } \mathrm{g} \text { VSS per } \mathrm{d}\right)\end{array}$ & $\begin{array}{l}\mathrm{CH}_{4} \text { production rate } \\
\left(\mathrm{mmol} \mathrm{CH}_{4} \text { per } \mathrm{g} \text { VSS per } \mathrm{d}\right)\end{array}$ \\
\hline Control & - & - & $0.53 \pm 0.01$ \\
\hline $0.04 \mathrm{~atm}$ & $1.67 \pm 0.24$ & $0.82 \pm 0.05$ & $0.70 \pm 0.02$ \\
\hline $0.88 \mathrm{~atm}$ & $1.94 \pm 0.12$ & $16.34 \pm 1.38$ & $4.08 \pm 0.71$ \\
\hline $1.54 \mathrm{~atm}$ & $1.90 \pm 0.41$ & $20.57 \pm 0.96$ & $4.19 \pm 0.54$ \\
\hline
\end{tabular}




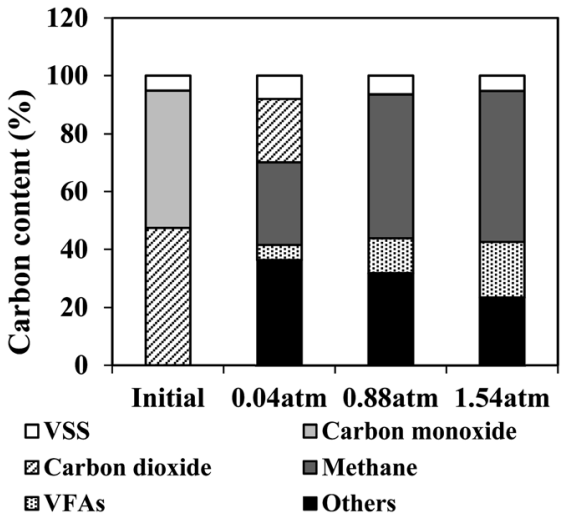

Fig. 5 Carbon balance analysis for the BFG fermentation by AGS at different $\mathrm{H}_{2}$ partial pressures on day 7 .

feasible, low hydrogen concentration needs to be maintained during the degradation of propionate and butyrate. ${ }^{37}$

$$
\begin{aligned}
\mathrm{CH}_{3} \mathrm{CH}_{2} \mathrm{CH}_{2} \mathrm{COOH}+2 \mathrm{H}_{2} \mathrm{O} \rightarrow & 2 \mathrm{CH}_{3} \mathrm{COOH}+2 \mathrm{H}_{2}, \\
& \Delta G^{0}=45.4 \mathrm{~kJ} \mathrm{~mol}^{-1} \\
\mathrm{CH}_{3} \mathrm{CH}_{2} \mathrm{COOH}+2 \mathrm{H}_{2} \mathrm{O} \rightarrow & \mathrm{CH}_{3} \mathrm{COOH}+3 \mathrm{H}_{2}+\mathrm{CO}_{2}, \\
& \Delta G^{0}=72.7 \mathrm{~kJ} \mathrm{~mol}^{-1}
\end{aligned}
$$

In this study, VFAs degradation seemed to be inhibited at $P_{\mathrm{H}_{2}}$ up to $1.54 \mathrm{~atm}$, which was mainly composed of acetic acid, butyric acid and valeric acid. Meanwhile, the remaining VFAs species and their concentrations under $P_{\mathrm{H}_{2}}=0.88$ atm were almost similar with those of the control. This observation suggests that proper exogenous hydrogen can improve the biomethanation of BFG by using AGS.

\section{Carbon balance}

To monitor the anaerobic process and compare the participation of the main substances related to BFG fermentation, the carbon balance was also analyzed in this work (Fig. 5). During the biomethanation of BFG using AGS, carbon from VSS of AGS and $\mathrm{BFG}\left(\mathrm{CO}\right.$ and $\left.\mathrm{CO}_{2}\right)$ may be converted to products including methane, carbon dioxide, VFAs and other substances. As seen from Fig. 5, all $\mathrm{CO}$ under different tested conditions were consumed within 7 days, producing methane and VFAs as the major intermediate carbon products under higher $P_{\mathrm{H}_{2}}$ conditions ( 0.88 and $1.54 \mathrm{am}$ ), and the percentage of methane-C was found to increase with the increase of $P_{\mathrm{H}_{2}}$ (around $28 \%, 49 \%$, and $52 \%$ at $0.04 \mathrm{~atm}, 0.88 \mathrm{~atm}$, and $1.54 \mathrm{~atm}$, respectively). Noticeably, $\mathrm{CO}_{2}$ was not fully utilized at $P_{\mathrm{H}_{2}}$ of $0.04 \mathrm{~atm}$, most probably due to its insufficient hydrogen. Restated, a slight increase in methane production was detected under $P_{\mathrm{H}_{2}}$ of 1.54 atm in comparison to $0.88 \mathrm{~atm}$, due to its higher accumulation of VFAs (19\%) in the fermentation systems.

\section{Conclusions}

This work indicates that AGS possesses high potential for anaerobic conversion of $\mathrm{CO}$ from BFG to methane via VFAs (especially acetate) or $\mathrm{H}_{2}$ as intermediates under mesophilic conditions. By using the simulated $\mathrm{BFG}$, the batch tests demonstrated that either $\mathrm{CO}$ or $\mathrm{CO}_{2}$ from BFG could be effectively converted by supplying exogenous hydrogen under an appropriate $P_{\mathrm{H}_{2}}\left(0.88 \mathrm{~atm}\right.$ in this study). Although $P_{\mathrm{H}_{2}}$ of 1.54 atm could rapidly convert carbon source in BFG to methane, the accumulation of VFAs implies that additional design and operation should be considered for the whole BFG fermentation system.

\section{Conflicts of interest}

There are no conflicts exist.

\section{Acknowledgements}

This work was financially supported by JFE steel cooperation.

\section{References}

1 GIO (The Greenhouse Gas Inventory Office of Japan), National Greenhouse Gas Inventory Report of JAPAN, 2017.

2 K. Goto, H. Okabe, F. A. Chowdhury, S. Shimizu, Y. Fujioka and M. Onoda, Int. J. Greenhouse Gas Control, 2011, 5, 1214-1219.

3 B. Molitor, H. Richter, M. E. Martin, R. O. Jensen, A. Juminaga, C. Mihalcea and L. T. Angenent, Bioresour. Technol., 2016, 215, 386-396.

4 X. Paubel, A. Cessou, D. Honore, L. Vervisch and R. Tsiava, Proc. Combust. Inst., 2007, 31, 3385-3392.

5 P. C. Munasinghe and S. K. Khanal, Bioresour. Technol., 2010, 101, 5013-5022.

6 E. Oelgeschläger and M. Rother, Arch. Microbiol., 2008, 190, 257-269.

7 W. H. Chen, M. R. Lin, T. S. Leu and S. W. Du, Int. J. Hydrogen Energy, 2011, 36, 11727-11737.

8 S. Esquivel-Elizondo, A. G. Delgado, B. E. Rittmann and R. Krajmalnik-Brown, Biotechnol. Biofuels, 2017, 10, 220.

9 Y. Rao, J. Wan, Y. Liu, I. Angelidaki, S. Zhang, Y. Zhang and G. Luo, Water Res., 2018, 139, 372-380.

10 M. Köpke, C. Mihalcea, F. Liew, J. H. Tizard, M. S. Ali, J. J. Conolly, B. Al-Sinawi and S. D. Simpson, Appl. Environ. Microbiol., 2011, 77, 5467-5475.

11 M. Balat, Int. J. Hydrogen Energy, 2008, 33, 4013-4029.

12 G. Luo, W. Wang and I. Angelidaki, Environ. Sci. Technol., 2013, 45, 2006-2012.

13 E. C. Bugante, Y. Shimomura, T. Tanaka, M. Taniguchi and S. Oi, J. Ferment. Bioeng., 1989, 67, 419-421.

14 S. S. Navarro, R. Cimpoia, G. Bruant and S. R. Guiot, Front. Microbiol., 2016, 7, 1-13.

15 Y. Zhang, J. Liu, W. Ding and X. Lu, Fuel, 2011, 90, 324-330. 16 S. Kim, K. Choi and J. Chung, Int. J. Hydrogen Energy, 2013, 38, 3488-3496.

17 Y. Hu, X. Hao, D. Zhao and K. Fu, Chemosphere, 2015, 140, 34-39.

18 C. W. Nam, K. A. Jung and J. M. Park, Bioresour. Technol., 2016, 211, 478-485. 
19 S. Esquivel-Elizondo, A. G. Delgado, B. E. Rittmann and R. Krajmalnik-Brown, Biotechnol. Biofuels, 2017, 10, 220.

20 C. F. Shen, N. Kosaric and R. Blaszczyk, Appl. Microbiol. Biotechnol., 1993, 39, 132-137.

21 F. A. Macleod, S. R. Guiot, J. W. Costerton and C. Hp, Appl. Environ. Microbiol., 1990, 56, 1598-1607.

22 Y. Liu, J. Wan, S. Han, S. Zhang and G. Luo, Bioresour. Technol., 2016, 202, 1-7.

23 S. R. Guiot, R. Cimpoia and G. Carayon, Environ. Sci. Technol., 2011, 45, 2006-2012.

24 Y. Zhang, Z. Zhang, K. Suzuki and T. Maekawa, Biomass Bioenergy, 2003, 25, 427-433.

25 S. S. Navarro, R. Cimpoia, G. Bruant and S. R. Guiot, Can. J. Microbiol., 2014, 60, 407-415.

26 J. Sipma, P. N. L. Lens, A. J. M. Stams and G. Lettinga, FEMS Microbiol. Ecol., 2003, 44, 271-277.

27 L. Maya-Altamira, A. Baun, I. Angelidaki and J. E. Schmidt, Water Res., 2008, 42, 2195-2203.
28 J. Sipma, R. J. W. Meulepas, S. N. Parshina, A. J. M. Stams, G. Lettinga and P. N. L. Lens, Appl. Microbiol. Biotechnol., 2004, 64, 421-428.

29 H. Heiskanen, I. Virkajärvi and L. Viikari, Enzyme Microb. Technol., 2007, 41, 362-367.

30 L. Appels, J. Baeyens, J. Degrève and R. Dewil, Prog. Energy Combust. Sci., 2008, 34, 755-781.

31 M. Braun and G. Gottschalk, Zentralblatt für Bakteriologie Mikrobiologie und Hygiene: I. Abt. Originale C: Allgemeine, angewandte und ökologische Mikrobiologie, 1982, 3, 368-376.

32 A. T. Johns, J. Gen. Microbiol., 1952, 6, 123-127.

33 Y. Jing, S. Campanaro, P. Kougias, L. Treu, I. Angelidaki, S. Zhang and G. Luo, Water Res., 2017, 126, 19-28.

34 R. Z. Gaur and S. Suthar, J. Cleaner Prod., 2017, 164, 557-566.

35 G. Luo, S. Johansson, K. Boe, L. Xie, Q. Zhou and I. Angelidaki, Biotechnol. Bioeng., 2012, 109, 1088-1094.

36 A. Pauss, G. Andre, M. Perrier and S. R. Guiot, Appl. Environ. Microbiol., 1990, 56, 1636-1644.

37 V. Siriwongrungson, R. J. Zeng and I. Angelidaki, Water Res., 2007, 41, 4204-4210. 